\title{
EL ZOO DE PAPEL: UN ANALISIS DE LA IMAGEN CIENTIFICA SOBRE LOS ANIMALES EN EL SIGLO XVIII
}

\author{
Antonio E. de Pedro
}

En uno de los libros más fascinantes sobre la Historia del Arte, Arte e Ilusión de E. M. Gombrich, se hace referencia a la imagen que sobre el «rinoceronte» grábara el artista alemán A. Durero (año de 1515) (1). Señala Gombrich cómo esta imagen se mantuvo vigente como modelo de identificación y reconocimiento de este animal durante más de dos siglos, cuando. bien entrado en el dieciocho, el naturalista inglés James Bruce publicó otra imagen, tomada del «natural», con la que quería demostrar la falsedad del grabado de Durero. Era la de Bruce una representación que apoyada en el valor del reconocimiento in situ (del «natural»), se convertía en la razón esgrimida con mayor peso frente a la imagen anterior tomada solamente de referencias. Gombrich relata en su libro cómo ese valor que Bruce atribuyó a su imagen y sirvió para desprestigiar la obra del artista alemán, no era realmente cierto:

\footnotetext{
«Porque la ilustración, presentada con tanto trompeteo, no está ni mucho menos libre de "prejuicios preconcebidos" ni del obsesivo recuerdo del grabado de Durero. No sabemos exactamente qué especie de rinoceronte vio el artista en Ras el Fil, y es pues posible que no sea del todo equitativa la comparación de su dibujo con una fotografía tomada en Africa. Pero me
} 
dicen que ninguna especie conocida por los zoólogos corresponde al grabado que se pretende tomado "al vif» (2).

Este ejemplo que he reseñado sobre uno de los casos más conocidos de representación zoológica «fraudulenta», me sirve, en este trabajo, para referirme sobre el aspecto de las representaciones gráficas tomadas del «natural» y sus incidencias y características en la ilustración científica del Dieciocho.

Las representaciones gráficas tomadas del «natural» se convirtieron, durante el Dieciocho, en un valor diferenciador entre una imagen identificada como auténtica y. una imagen falsa, con pretensiones de auxilio científico. Con la incorporación de artistas en los grandes viajes naturalistas realizados en el siglo, se vio garantizada la validez de las obras. Extrañas y exóticas plantas fueron apareciendo en voluminosos álbumes sobre la flora y la fauna de zonas como América, Africa, Australia, etc. Las imágenes recogidas por los artistas llegaron donde no lo podían hacer cientos de herbarios de especies recopiladas o docenas de esqueletos de curiosos animales antes nunca vistos. Las imágenes se convierten, gracias al valor «del natural", en vehículos indiscutibles del saber científico de la época recorriendo las salas de las facultades dedicadas al estudio de la naturaleza o pasando a engrosar las magníficas bibliotecas de los más famosos Gabinetes Naturalistas de Europa. En sus representaciones las imágenes científicas abordan todo el complicado y sistemático entretelado de la ciencia empirista, en sus cientos de descripciones y clasificaciones; de tal manera que las imágenes tomadas del «natural» se convirtieron por uso y definición en objetos científicos de estudio, pertenecientes a una Ciencia profundamente iconista.

Ahora bien, cabe preguntarnos al hilo de esta reflexión, si estas circunstancias situadas entre el uso y la superación de las representaciones entendidas como arquetipos (caso de las imágenes aportadas por Durero y Bruce) (3), y el carácter de suma validez con el que së clasifican, pueden considerarse como generalidades extensibles a producciones creadas en similares circunstancias o bien se puede afirmar que las representaciones gráficas realizadas dentro de un proyecto con intenciones científicas responden a una validez incuestionable desde el punto de vista de la observación y el estudio naturalista. Es mạ́s, las imágenes naturalistas que sobre animales se realizaron durante el Dieciocho español, ¿son representaciones que, aún siendo captadas del «natural» pueden verse influenciadas por «juicios preconcebidos»? 
Son cuestiones como éstas las que me animan para desarrollar este estudio. Máxime cuando asistimos -en algunos casos como protagonistas y en otros como simples espectadores- al desarrollo de un debate social e histórico en el que se cuestionan aspectos tan relevantes para la concepción de Ciencia como la Modernidad, la Ilustración, el Racionalismo, etc.; fenómenos históricos, todos ellos, de una significación especial para la llamada "cultura occidental». Deseosos de que este debate se abra a contenidos y posiciones entendidas como «no oficiales», pero, sin duda, deseosas de aportar consideraciones progresistas sobre el conocimiento de nuestra cultura y, en especial, al estudio de las relaciones arte-ciencia, brindo mi participación, en espera de que mis opiniones contribuyan, de alguna forma, a su concreción.

1. El naturalismo y lo natural en las representaciones sobre animales

Desde épocas remotas, las representaciones sobre animales siempre han tenido un interés destacado para la humanidad. El animal ha sido para nosotros un fiel compañero de trabajo, un elemento incuestionable de su dieta alimenticia o un motivo de sus.intereses religiosos. Las representaciones gráficas sobre animales han recorrido una larga trayectoria histórica desde su aparición en las grutas y santuarios mágicos del neolítico, hasta las más representativas imágenes de nuestra cultura actual. Los animales han estado siempre presentes en las esferas de nuestras relaciones humanas y sociales. Su papel ha ido emparejado a una cultura basada en un predominante homocentrismo, que ha dictaminado nuestras relaciones con la naturaleza y, muy especialmente, con los otros seres que la pueblan de acuerdo a las referencias que pudiéramos obtener de su conducta, diferenciando actitudes menos hostiles o en franca confrontación a nuestra presencia. La humanidad, como ha hecho con la mayoría de los seres y objetos sobre lós que pretende extender su influencia, no sólo ha reconducido hábitos y costumbres en favor de su propio beneficio, sino que ha utilizado las imágenes de los animales como un medio de referencia de un determinado tipo de manifestación cultural entre otras de distinto carácter, constituyendo una muestra palpable de su creencia en la perdurabilidad de la especie humana y un motivo ornamental y de gozo de sus necesidades estéticas a lo largo de la historia. Ciertamente, el hombre le ha ido poniendo "el nombre a los animales" y ha terminado por confeccionarles una 
imagen. Imágenes y formas que han ido cambiando de acuerdo con las necesidades propuestas por un determinado grupo humano, por una determinada clase social o por una determinada sociedad. Alabó y. alaba en estas imágenes sus cualidades como seres voladores, la consistencia de sus garras o la fiereza de su carácter, el beneficio de su compañía, la complejidad de sus estructuras internas, la rareza y lo exótico de sus manifestaciones. Con todo ello fue confeccionando un inmenso album dispuesto a ser utilizado por artesanos, dibujantes, escultores, cazadores, naturalistas, anatomistas, escritores; en fin, todo aquél que pretendiera un modelo de representación o de estudio en el que apoyar sus actividades.

Tal vez fueron los llamados animales salvajes los primeros en ser "retratados». Más tarde llegarían los domésticos, los alejados y extraños, ligándolos, en algunos casos, a las leyendas y mitologías o asignándoles aspectos relativos a las pasiones humanas: la bondad, el terror, el pecado, el placer. El hombre no sólo los dotó con categorías, "reflejo» de sus propias concepciones morales, sino que configuró arquetipos de su propia conducta en los que se ponían de manifiesto aquellos rasgos del animal fruto de su admiración: el hombre-lobo, el hombre-vampiro, el hombre-mosca, etc. En el caso de algunos artistas del Dieciocho, como el del francés Charles Le Brun, las relaciones fisionómicas entre ciertos animales y rostros humanos son evidentes, en un intento por obtener una imagen que represente las pasiones del alma (4). La idea de Le Brun tampoco era nueva. Ya G. B. Della Porta, artista italiano del Renacimiento, se había adelantado a estos planteamientos en su obra Humani Physiognomia (5), aportando los modelos de referencia a la obra del artista francés.

No sólo fueron las asociaciones humano-animal y animal-humano las que han preocupado a una cierta práctica artística. Las mismas asociaciones entre los distintos tipos de animales han sido tratadas configurando parte importante del llarnado "Zoo de papel»: caballo con alas, perros con garras de ave, dragones, etc.; todos ellos en un intento por seguir asociando categorías previamente establecidas. De todas estas representaciones - y muchas más que pudiéramos significar en voluminosos tratados sobre la ilustración con y sobre los animales- resaltamos la fuerza con la que el hombre se «ciñe» a las representaciones basándose en formas y planteamientos naturalistas. Se puede ser más o menos esquemático, en mayor medida abundar en detalles descriptivos, pero lo que resulta evidente, y no por ello menos interesante, es el esfuerzo que ha realizado por presentar imágenes asumibles por los ambientes «oficiales» de la sociedad. Asumibles en aquellos rasgos y valores que suponen las alas de un ave insertadas 
en el cuerpo de un caballo o, por el contrario, la figura de una «rata voladora» introducida en el decorado de un paisaje con una figura diseccionada en la parte superior (Fig. 1). Entre ambas representaciones, fruto de dos concepciones distintas de lo que debe ser el papel a cumplir por las imágenes sobre animales, aún podemos «rastrear» similitudes que se manifiestan en la forma y en la manera que son tratadas. En la primera de las imágenes, la idea del "Pegaso» como caballo volador, se expresa descriptivamente como un caballo con alas. En la segunda, se muestra el cuerpo de la rata y se realiza una descripción interna y externa, resaltando las razones anatómicas que posibilitan que el animal pueda realizar una acción asociada con el «vuelo». En ambas, la descripción —en una más detallada que en la otra- se convierte en el instrumento; la forma naturalista, en la posibilidad de expresar una determinada concepción entre ambos elementos. Para nada cuenta, en estos casos, que estemos ante dos imágenes distintas: una, producto de una creencia mitológica y, la otra, producto de la observación empírica de la realidad. Para los contenidos expresados en la forma naturalista las dos pueden ser asumibles. Su aceptación social como imágenes representativas de una realidad, no está dada por el valor formal de su representación, sino por las circunstancias en las que la forma sólo actúa como un instrumento para explicar el mundo. La imagen del "Pegaso» no necesita pasar la prueba de su existencia real, basta con que su representación sea verosímil.

Los aspectos por los cuales se establece la identificación, aquéllos que van más allá del reconocimiento naturalista convirtiéndose en elementos designativos, sólo se alcanzarán cuando la imagen deje de tener valor descriptivo y asuma el carácter de la idea que la sociedad pretende encontrar representada en la imagen.

No obstante, hay entre ambas imágenes un aspecto de especial significación en cuanto a los elementos formales naturalistas que se manejan y que marcan una notable diferencia. En el caso de la representación de la "rata voladora», no sólo hay un interés por la identificación y por hablarnos de lo que es, sino que hay un interés mayor por explicarnos cómo es; siendo esta circunstancia la que posibilita la anterior. Por su parte, la representación del «Pegaso» responde a la consecución visual de una idea que permite la comparación entre ésta y su imagen. En el caso de la «rata voladora» el naturalismo se propone como un procedimiento explicativo, una valoración de la realidad, pretendiendo su significación no sólo como imagen que actúa en lugar de si no como realidad valorada. Es decir, la composición se articula gracias al lenguaje naturalista de las formas mane- 
jadas, pero en ese afán por explicar la realidad, ésta se ve superada al actuar la imagen no tanto como "reflejo» de lo que un «ojo capta», como al actuar de objeto de estudio y, por tanto, objeto de la realidad. En este sentido, la imagen de la "rata voladora» se ve inmersa en un panorama de concepciones e ideas que admiten los elementos valorativos de significación naturalista como principios dinamizadores del conocimiento científico. Este planteamiento, presente a lo largo del siglo XVIII, se aleja de las propuestas expresadas en la imagen del "Pegaso», donde el lenguaje naturalista formal es sólo un medio eficaz de expresión, evitando ascender a planteamientos valorativos de la realidad natural.

2. La imagen científica de los animales en el siglo XVIII: antecedentes e influencias

El siglo XVIII puede considerarse un siglo espectacular en el desarrollo de la Historia Natural. Muchos fueron los factores que contribuyeron al despegue experimentado por disciplinas como la botánica, la zoología, la mineralogía, la astronomía, etc. No es mi intención, en este artículo, realizar una enumeración detallada de todos ellos. No obstante, he de decir que las imágenes científicas son el resultado de indudables transformaciones en la manera de entender las Ciencias Naturales.

Durante años, incluso hoy, es frecuente leer juicios y análisis superficiales sobre el papel que las imágenes artístico-científicas han desempeñado en el quehacer y desarrollo de las ciencias. Las consideraciones más benévolas no traspasan un falso prejuicio sobre su labor de "auxilio". Afortunadamente, estos aspectos cambian, aunque sea muy lentamente y a fuerza de que la historia de los hechos actúa contra los «corsés» impuestos desde las plumas y tribunas más reaccionarias. Es decir, planteamientos realizados desde una concepción de super-especialización del pensamiento tecnológico actual que traslada mecánicamente coordenadas y juicios críticos propios de nuestro tiempo a situaciones históricas en las que no tienen cabida. En este sentido, los planteamientos por los que se movía la ciencia del Dieciocho constituyen ejemplos que auguran una desmitificación de aquéllos que entienden las ciencias experimentales, como un "coto» propio de tecnólogos, aferrados a una verdad inalterable, inamovible y aséptica.

Fue el Dieciocho un siglo en el que se gestaron las bases de lo que hoy conocemos como imágenes científicas o imágenes artístico-científicas (6). 
Con la aparición de la fotografía, a finales del siglo XIX, las imágenes científicas basadas en el procedimiento gráfico fueron perdiendo la fuerza que les ofrecía saberse poseedoras del «monopolio de la comunicación». Hoy en día, el dibujo, el grabado científico, no sólo ocupa un lugar importante frente a su «rival» más directo, la fotografía y los sistemas de reproducción fotográficos (el cine, el vídeo, las imágenes por ordenador, etc.), sino que es consciente de que ofrece un producto distinto. Afianzado en principios y pretensiones que son el resultado de su desarrollo histórico.

El caso de las imágenes científicas sobre animales tiene sus claros precedentes en producciones anteriores, no de una manera lineal ni directa, ni tampoco de forma inalterable a nivel de zonas geográficas distintas, sino como consecuencia de procesos intensamente ligados al desarrollo y las necesidades de la Ciencia, por un lado, y a la fluctuación sufrida por la demanda de unas determinadas formas y planteamientos de expresión estéticos, gracias a procesos artísticos ligados a los determinados países.

Es en este estado de cosas, en el que la aparición de los modelos gráficos de representación científica sobre los animales encuentran su concreción. Unos obteniendo - llamémoslo así- un mayor éxito social al instaurarse dentro de una "oficialidad» científica; mientras que otros actúan de forma. «marginal»; aunque esta «marginalidad» capitaliza cierto valor histórico al convertirse en modelos alternativos que pueden incidir en las transformaciones y modalidades propias de cada país.

En España la situación fue similar a la del resto de Europa, (aunque cada caso requiere un estudio particular de las condiciones por las que atraviesan sus imágenes científicas) bien porque España no tuvo un papel significativo en este campo hasta que se inició en nuestro país un proceso renovador de las artes y las ciencias producto del ascenso al Estado de grupos de orientación ilustrada; bien porque España siempre sufrió cierta deficiencia en el campo del grabado y los procesos de reproducción gráficos. Nuestro país desarrolló unas imágenes científicas sobre los animales que fue en progresión desde las más abiertas posturas decorativas y ornamentales hasta el desarrollo de una temática individualizada y formalizada en la segunda mitad del siglo. Anteriormente al Dieciocho, sólo tenemos conocimiento de algunos ejemplos aislados, donde el naturalismo se atisba más como una realidad en formación que como un hecho consumado. Esta situación está presente en obras tan significativas del panorama español como: Acerca de la materia medicinal y de los venenos (1563), de Pedacio Dioscorides Anazarbeo; Tratado de las drogas y medicinas de las Indias Orientales (1587), de Cristobal Acosta; Conocimiento de las diez aves meno- 
res de jaula, su canto, enfermedad, cura y cría (1604) del residente en Corte, Juan Bautista Xamarro. Todas ellas se caracterizan por significar un cambio en el tratamiento de las figuras de los animales, propiciando representaciones más proclives a un naturalismo formal, más descriptivo y menos esquemático.

\subsection{La obra de la grabadora M. ${ }^{a}$ Eugenia de Beer}

Entre 1640 y 1652, la artista flamenca afincada en España, María Eugenia De Beer, grabó para el Príncipe Baltasar Carlos veintitrés figuras de aves acompañadas de una dedicatoria en verso. Fue la joven De Beer una de nuestras primeras grabadoras. Hija del pintor grabador Cornelio De Beer, desarrolló desde muy joven sus amplias actitudes artísticas, apareciendo como grabadora en Madrid entre los años de 1640 al 1652, para desaparecer todo rastro conocido de sus actividades a partir de esta fecha; tal y como lo pone de relieve el investigador español Juan Carrete Parrondo (7).

De su obra Aves para el Príncipe, agradable y divertida, preocupada por presentar un grabado «limpio» y de una gran técnica, Carrete Parrondo destaca que ésta se encuentra en el mismo ámbito de intenciones que las que Juan Bautista Xamarro propone en su estudio sobre las diez aves menores de jaula. Pues tanto la obra de la flamenca como la del madrileño, pretenden "gustar y satisfacer», siendo similares a las que por esa época se podían realizar en Italia o en los Países Bajos (8). Aun admitiendo esta afirmación de Carrete Parrondo como acertada, las imágenes construidas por De Beer van más allá. Ciertamente, su obra no puede ni debe entenderse como una obra de características científicas, y ni siquiera resistiría la comparación con otras obras europeas que sí tienen una clara intención en este sentido. Pero esta situación no menosprecia nuestro interés, afirmando que De Beer recurre a planteamientos compositivos y formales muy propios de las imágenes científicas. Incluso su mensaje, las características de su información, no se detienen en meros planteamientos ornamentales o de entretenimiento: su postura informativa encierra otro "principio motor» en su relación con el lector. Un principio que entra de lleno dentro de la esfera de lo científico.

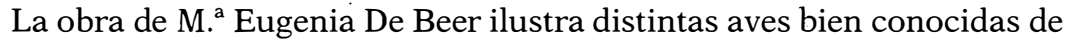
nuestro país (9). Las representaciones se delimitan por la inclusión de un 
marco interior, elemento compositivo que también está presente en otro tipo de imágenes científicas como, por ejemplo, las botánicas (10). En el interior de este marco se introducen elementos de ambientación definidos por el profesor Joaquín Maluquer, de la Sociedad Española de Ornitología (11), como elementos que acompañan y "amenizan» las composiciones: ramas, plantas, insectos, trazados con cuidado y en detalle, propio de la pintura flamenca del Diecisiete. A este respecto quisiera puntualizar que estos elementos de ambientación son, a su vez, complementos informativos de marcada significación. Su inserción y elección están justificados en tanto en cuanto reafirman el carácter de verosimilitud espacial que persigue la artista, y colaboran en el suministro de una información complementaria al reconocimiento del ave, planteándonos cuestiones referidas al tipo de habitat, alimentación y modos de apropiación de estos alimentos. Hay, asimismo - y en este sentido también realizan una valiosa aportación-, un decidido intento por evitar que las figuras adquieran un hieratismo o rigidez extrema. Propician, desde una continuada insistencia en la forma naturalista, que la imagen alcance un grado de verosimilitud muy amplio y todos los elementos representados se justifiquen desde esta actitud. De este modo, la ambientación, a la que hace referencia el profesor Maluquer, se ve "provocada», propiciada, desde el recurso del lenguaje naturalista y sus intenciones de verosimilitud. Asimismo, la presencia de elementos como plantas, insectos, va más allá de esta actitud ambiental tal y como ya he señalado. La escenificación de la caza de insectos por parte del Caponero, por ejemplo, redunda en el hecho de su condición de ave insectívora por excelencia (Fig. 2). De igual forma, la ubicación del Cardelillo posado en un cardo, del que deriva su nombre, se convierte en un nuevo complemento de información; a la vez, que la artista utiliza el cardo como un elemento de apoyo y, por tanto, de verosimilitud naturalista (Fig. 3).

Como vemos, los ejemplos son significativos. No obstante, encontramos dentro de esta misma línea de actuación, dos grabados de dos especies de rapaces que me gustaría detenerme en el análisis de algunas de sus características. Se trata del Xernicola y el Ilchiu (Figs. 4 y 5). Rapaces ambas, pero de distinta costumbre cazadora: diurna el Xernicola (Falco Tinnunculus) y nocturna el Ilchiu (Otus scops). Es exactamente esta característica la que De Beer pone en evidencia en sus dos grabados. La lámina que representa a la figura del Xernicola, aparece acompañada de dos insectos: una libélula y una pequeña mariposa diurna. Una consulta especializada sobre el habitat y costumbres de esta rapaz, nos confirma sus actividades cazadoras diurnas y. su alimentación basada en pequeños mamíferos, aves, y reptiles 
e insectos diurnos. Dejemos por el momento en suspenso la explicación de la imagen y pasemos al estudio del segundo grabado.

En el caso del Ilchiu, éste también aparece acompañado de la figura de un insecto: una mariposa nocturna. Realizando, asimismo, una consulta especializada, comprobamos que su dieta alimenticia se basa fundamentalmente en el consumo de invertebrados y sus actividades de caza son preferentemente nocturnas.

Ahora bien, a la vista de lo que aquí hemos expuesto podemos realizarnos las siguientes preguntas: ¿Cuál es el papel que juegan en estos dos casos los elementos complementarios de información? ¿De qué manera, en qué sentido, estos elementos condicionan o complementan la lectura de las imágenes?

La respuesta a la primera de las preguntas nos da como resultado que se desarrolla una función similar a los casos citados del Cardelillo y también del Rosignolo: se muestran insectos que forman parte de su dieta alimenticia. Pero, asimismo, nos encontramos con un nuevo tipo de «mensaje informativo" que ya no tiene referencia con el tipo de alimentación que tienen ambas rapaces, pero sí redunda en su condición de rapaz nocturna o diurna. Los insectos, por su propia condición de nocturnidad y carácter diurno y al establecerse una relación compositiva (forman parte de una misma imagen), provocan, a su'vez, preguntas y respuestas en relación con la conducta del ave: ¿Si el Ilchiu caza de día, entonces cazará mariposas diurnas? ¿Si el Xernicola caza de noche, entonces cazará mariposas nocturnas? Pero las interrogantes se pueden invertir: ¿Si aparece una mariposa nocturna en la representación del Xernicola, entonces es que caza mariposas nocturnas? $\mathrm{O}$, entonces, ¿ es un ave que caza de noche, independientemente que cace mariposas o no?; que, además, las caza. En el caso del Ilchiu podríamos realizar el mismo tipo de pregunta. Por tanto, y entramos de lleno en la contestación de la segunda interrogante que hacíamos al principio, la respuesta la podemos cifrar en dos ámbitos. Un ámbito que parte de la definición de imágenes divulgativas, además de entretenidas, con intenciones cientifistas. Es decir, representaciones que partiendo del empleo de un léxico artístico de carácter naturalista establecen estructuras con calidades expresivas de carácter científico. Y un segundo ámbito, que se puede constatar en el.hecho de que estamos frente a representaciones artísticas posibilitadas desde el plano y conocimiento de procedimientos artísticos, que provocan una lectura artística, en el sentido de un determinado tipo de conocimiento. Ahora bien, dado que su convocatoria viene en atención al grado de conocimiento específico que posea 
el lector, ambos ámbitos se plantean al unísono, pero no pueden leerse por así decirlo- al mismo tiempo. El ejercicio de una determinada posibilidad de lectura omite o excluye a la otra.

\section{El siglo XVIII y los modelos de representación científica}

A mediados del siglo XVIII apareció en Francia la obra naturalista Historia Natural General y Particular del Conde Buffon (12) de marcada significación y trascendencia en el estudio de las especies naturales. En España la obra de Buffon fue traducida del francés por José Clavijo y Fajardo para la imprenta madrileña Ibarra, entre los años 1785 y.1805. La primera publicación constaba de 21 volúmenes, mientras que en 1835 se publicaron los tomos 22 y 23 de la misma. Obra profusamente ilustrada por artistas españoles (13), supuso, en este sentido, un espaldarazo definitivo en la ilustración de animales para libros científicos. Las posturas precientíficas desarrolladas en las obras de M. ${ }^{a}$ Eugenia de Beer y. Joaquín Xamarro vieron desarrollados sus postulados en las ilustraciones de este tipo de libros; teniendo su aparición un tipo de diseño dispuesto a poner de relieve las formas anatómicas, mientras que, en otros casos, el desarrollo de las representaciones escenográficas (14) también encontró cumplido afianzamiento.

En este siglo, además de la aparición de obras con un marcado carácter totalizador y enciclopédico (caso Buffon) encontramos otras específicas sobre aspectos determinados o sobre distintos géneros de animales: aves, cuadrúpedos salvajes, marinos, etc. De tal manera que en este desarrollo imparable hacia la diversificación del estudio natural y con el de la múltiple variedad de imágenes sobre la naturaleza, se propugnó una fuerte especialización del lenguaje iconográfico científico. Detectamos preferencias de uso en los «roles» a jugar por los elementos de representación. Por.ejemplo, en las ilustraciones sobre insectos, se aprecian, preferentemente; el uso de espacios neutros (15). Un caso similar se observa en las representaciones sobre peces, crustáceos o animales de la fauna marina y fluvial. En definitiva, se comprueba cómo determinados tipos, manifestaciones del lenguaje visual empleado durante el Dieciocho, se «ligan» a determinadas maneras de transcribir la realidad natural y la de los seres que la habitan.

En las páginas siguientes realizaremos un breve análisis de los modelos de representación científica más frecuentes en el siglo XVIII. Partiremos del 
estudio de distintos tipos de especies que, por otro lado, y como ya ha quedado señalado, adquieren una relevancia especial de preferencia a la hora de la creación de las imágenes. Centramos nuestras observaciones en el ámbito español, advirtiendo las repercusiones que en éste han tenido las influencias europeas.

\subsection{Aves}

Es frecuente encontrar en el Dieciocho extensos tratados sobre este tipo de animales; sin duda, uno de los grupos que mayor interés ha despertado en los estudios naturalistas de todas las épocas. Los modelos de representación iconográfica seleccionados durante este siglo, tienen sus mayores diferencias en el tipo de ambientaciones espaciales; escogiendo, preferentemente, entre las de características escenográficas o las de espacio neutro. En obras europeas como L'Histoire naturelle aclairciée dans une de ses parties del inglés John Ray, con grabados de François Nicholas Martinet, las ilustraciones sobre rapaces (caso del «águila Real») son similares a las realizadas por M. ${ }^{a}$ Eugenia de Beer en su obra para el Príncipe Baltasar Carlos: una escenografía limitada a los elementos de sustentación (ramas de árboles, troncos, etc.). No obstante, las representaciones de Martinet responden con una mayor claridad a planteamientos de identificación y clasificación, asociando las figuras a textos escritos que completan e intensifican la información. La presencia de estos textos fue nota frecuente en las láminas científicas del siglo. Del mismo modo, el naturalismo formal en el disegno de las figuras se convirtió en una actitud predominante. En algunas de las ilustraciones realizadas por Martinet, sobre todo aquéllas dedicadas a aves como el buho o la lechuza, encontramos construcciones espaciales especialmente dinámicas, en las que las figuras (se representan varias en una composición) contribuyen a crear una ilusión de perspectiva escalonada: la primera figura gira hacia la izquierda, la segunda lo hace a la derecha, la tercera se coloca de perfil actuando como elemento final o tope. Por su parte, los elementos sustentantes actúan como elementos de ambientación del espacio y como ordenadores espaciales; ya que sin su presencia no es del todo posible captar la ilusión de la perspectiva escalonada.

En otras imágenes sobre aves rapaces incluidas en la obra de Moritz Borkhausen, Teutesche Ornitologie (1800-1811), dibujadas y grabadas por 
J. C. Susemihl, encontramos soluciones similares a la labor encargada a los elementos sustentantes. En todo caso, las intenciones son artísticas y los elementos y antecedentes históricos de referencia también lo son. Por tanto, no podemos acceder plenamente a la información científica si antes no hemos tenido presente estas circunstancias como propuestas que responden a intenciones artísticas presentes de la época. Más que la verosimilitud naturalista de la escena, lo que se intenta es la creación del tipo; tal y como lo entiende el historiador italiano Giulo Carlo Argan (16).

En otras obras sobre aves, el planteamiento es bien distinto. Tanto en History of British Birds (1797-1804) de Tomas Bewick, como en Natural History of Birds (1802-1806) de George Edwards, las intenciones escenográficas van más allá (Fig. 6). En el «Ardea Herodias» de la obra de Edwards, se insiste en una escenografía que trasciende el "papel de decorado» convirtiéndose en parte importante del discurso científico. En este grabado se aprecia al "Ardea Herodias» captado en el preciso momento en que se abalanza sobre su presa. Es su habilidad para obtener el alimento la que elogia el artista y no su clasificación como un determinado tipo de ave. Por su parte, en algunas ilustraciones de la obra de Mark Casteby, Natural History of Carolina, Florida... (1754), ocurre el caso contrario. La escenografía del «Ardea Herodias» está concebida para resaltar el hecho de la habilidad del animal; los elementos de ese «decorado» sólo tienen sentido en función del desarrollo de esta cualidad que se le presenta al lector como una acción temporal. En el caso de los grabados de Casteby («Ceryle Alcyon») se nos proponen aspectos de carácter informático sobre sus costumbres alimenticias y, por tanto, sobre características propias de su especie.

En España, las obras dedicadas a estos temas tuvieron claras relaciones con las imágenes que. hemos analizado. Una obra como la reedición de la Historia Natural (1790) del griego Plinio recogía modelos en los que las composiciones se concebían bajo los mismos planteamientos de la obra de Moritz Borkhausen (caso del «águila real»). En otras imágenes como la del "Gallo y la Gallina» se aprecian posiciones cercanas a las ilustraciones de Martinet para la obra del Conde Buffon (Fig. 7).

\subsection{Mamiferos}

Entre 1671 y 1688 aparece en Europa la importante obra sobre animales, Mémoire pour servir à l'histoire naturelle des animaux de Cl. Perrault. 
Las ilustraciones fueron realizadas por el artista francés Sebastien Leclerc. Las composiciones de este artista poseen un sello particular. Este tipo de imágenes sobre animales, que hicieron de Leclerc un artista muy conocido en los medios naturalistas franceses del siglo XVII, tuvieron en España su parangón en los grabados anatómicos sobre el cuerpo humano del artista valenciano Crisóstomo Martínez (17). Tanto Leclerc como el español Martínez — salvando las diferencias temáticas propias de sus trabajos- nos introducen en composiciones con continuas referencias barrocas: los «juegos escenográficos» llenos de intenciones artísticas, los efectismos visuales, las composiciones construidas en dos niveles, etc.; en suma, un gran sentido de la «teatralidad». No obstante, y como cabría pensarse, estas características no constituyen un impedimento para que las imágenes cumplan eficazmente con su labor científica. Hay, por supuesto, una manifiesta inquietud estética que se pone de relevancia gracias a la puesta en marcha de un rico lenguaje artístico. Las composiciones de Leclerc y Martínez «reclaman» para la claridad expositiva de.la información científica, la riqueza del lenguaje artístico predominante en la Europa del Setecientos, de una manera franca, sin titubeos y no ocultando, ni "camuflando" su oficio de artista. Ponen de relieve dos aspectos fundamentales de las imágenes artísticocientíficas del siglo: el de las cosas vistas (parte inferior de las imágenes) y el de las cosas dibujadas (parte superior de las imágenes). Lo que es lo mismo: cosas vistas igual a objetos naturales de estudio; cosas dibujadas igual a objetós naturales estudiados. De tal manera, que el conocimiento de la naturaleza pasa por su concreción en una imagen (objetos estudiados) y, a su vez, se pone en evidencia que el estudio de la naturaleza puede ser producto de una experiencia artística.

Las alabanzas a un disegno, a un dibujo que cumpla un papel superador del primer contacto con la cosa natural, son aspectos que, llegado el Dieciocho, se magnifican aún más. Las imágenes abandonan el juego «teatral» y efectista de las composiciones de Martínez y Leclerc, adquiriendo otros planteamientos constructivos en consonancia con su tiempo; pero lo que no se rechaza en este siglo, lo que no se abandona, sino que al contrario, se desarrolla, es el papel transcendente y de conocimiento que tiene la experiencia artística. Se «apuesta» por un dibujo, como el medio por excelencia en la producción de unos instrumentos útiles en el estudio científico de la naturaleza.

En España, por su parte, se realizan publicaciones como la versión española de la obra del Conde Buffon (18), herederas de esta tradición. En láminas como la del «Orangután» o la del «Desmán», abundan detalles que 
reafirman las corrientes europeas en materia de ilustración científica. En el caso del «Orangután», la escena es rica en la exposición de detalles sobre su habilidad trepadora. La escenografía, como en el caso del «Ardea Herodias", se construye en función de resaltar esta cualidad. Contrariamente, en la imagen del «Desmán», la "puesta en escena» no se concreta en estos aspectos. Introduce la figura en una escenografía que «dice cosas de ella» al establecer una lectura asociativa entre los distintos elementos representados: la cercanía de un elemento acuático, la presencia de un bosque de coníferas, las viviendas que se encuentran en sus orillas. De tal manera, que la ambientación que rodea a la figura del «Desmán».sirve, sobre todo, para reconocer aspectos del habitat del animal (son testimoniales) y para ampliar un proceso asociativo-informativo: el «desmán» vive en zonas cercanas a lagos o ríos, en zonas de bosques con vegetación de clima frío (coníferas) y suele ser un animal que puede convivir con el hombre. La composición adquiere dimensiones de generalidad; se estudia el comportamiento del «Desmán» como especie, no como individuo. En este sentido, la imagen adquiere rango de representación de un tipo.

\subsection{Insectos y reptiles}

Para poder obtener un análisis preciso sobre las imágenes científicas de este tipo de animales en el siglo XVIII, debemos remontarnos al estudio de los modelos de representación presentes en el siglo anterior. Casos como la obra de la naturalista holandesa M. ${ }^{a}$ Sibylla Merian, Histoire des insectes de l'Europe dessinées d'après nature (1730) recogen todas las características de los estudios sobre Historia Natural que tanto interesaron a los científicos y artistas holandeses del Setecientos (19). En el Prólogo de su obra, Merian advierte de que sus observaciones fueron directas, así como su interés por no representar la figura aislada, sino dentro del entorno natural que las ve desarrollarse:

. «J'ai representée tous ses insectes sur les plantes, les fleurs, les fruits dont ils se nourrissent»(20).

Diseñadas por la misma Merian y grabadas por L. Mulder, P. Sluyter y D. Stoo Pendaat, las 62 planchas se construyen de forma muy interesante. En las láminas se describe el proceso y desarrollo de un insecto desde la 
larva hasta convertirse en adulto. Para ello se contempla, en algunas imágenes, los distintos pasos de transformación en un mismo plano espacial y temporal. Es decir: desde la Chenille, pasando por la oruga, hasta convertirse en mariposa. Descritos todos ellos en un mismo plano compositivo, en el que un elémento figurativo como el árbol actúa como el ordenador temporal en la secuencia del desarrollo del insecto. La imagen proporciona una doble lectura. Si contemplásemos una de esas láminas y nos pidiesen que diésemos una explicación de lo que observamos sin atender a las descripciones èscritas que la acompañan, seguramente nos decidiríamos por una relación del desarrollo del ciclo vital del insecto, entendiendo que estamos ante una representación que muestra distintas fases de este ciclo. La imagen se plantea como una unidad temporal y espacial, sin la posibilidad de ejercer una lectura fraccionada a no ser aquélla que se establezca al detenernos en determinado desarrollo del ciclo. Se confirma un microcosmos que poco tiene que ver con lo que sucede en la realidad de la naturaleza, siendo esta realidad la que, por medio de la representación, se intenta interpretar. En este caso, el texto descriptivo, esa memoria de apoyo que acompaña a las imágenes y al que recurre el especialista, se convierte en la clase de significación científica; ya que en él residen las soluciones que hacen superar las contradicciones en las que incurre la imagen.

A medida que transcurre el Dieciocho, este modelo pierde vigencia y las láminas sobre insectos y reptiles aparecen faltas de toda escenografía. Se construyen dentro de lo que hemos denominado espacio neutro. Veamos algunos ejemplos.

Entre 1740 y 1759, año de su muerte, August Johann Roesel Von Rosenhof realizó uno de los más insignes trabajos en la ilustración sobre insectos (21). Anticipándose a su contemporáneo Buffon en la aparición de los tres primeros volúmenes de su Historia Natural (1749), Roesel realizó una obra con más de 300 grabados sobre distintas clases de insectos. La mayoría de estos grabados se caracterizan por la utilización de fondos de espacio neutro, desarrollando las posibilidades de establecer generalidades sobre determinada especie, eliminando rasgos de individualidad. En trabajos como los realizados por este naturalista alemán, las concepciones espaciales sólo tienen valor en relación con el «sujeto» que las propicia. Es decir, en casos como los de las mariposas, las figuras n. ${ }^{\circ} 4$ y 5 contrastan con el espacio de la figura 2; mientras la figura 6 pude aceptar algunas variantes: puede estar posada sobre una superficie indefinida, en vuelo y vista desde arriba. En ese sentido, la obra de Roesel pertenece a una tradición artística en el diseño de animales ya presente en Europa en el siglo XVI y 
que, muy concretamente, Gombrich recoge en uno de sus libros.(22). Me refiero a los trabajos de J. Hoefnagel, del Archetypa studiaque (1592), en los que el investigador austriaco encuentra especial interés:

«(...), con su decorativa reunión de plantas y animales, suplimos el fondo adecuado para cada figura: el lagarto está tendido en una pendiente, mientras ciertos insectos, que arrojan sombras, vienen imaginados sobre un fondo plano, y a otros se les ve volando. Sin darnos cuenta, hemos efectuado una rápida sucesión de pruebas de coherencia, y hemos elegido las lecturas que ofrecen un sentido» (23).

Los trabajos de Roesel, incluso los de Hoefnagel más cercanos en el tiempo, rompen la unidad temporal que hemos visto en los trabajos de Merian. La imagen nos induce a una lectura "a saltos", en busca de esa coherencia a la que Gombrich hace referencia. En este caso, las señales referenciales que conectan la imagen con el texto se convierten en elementos claves, capaces de vehicular las distintas figuras, provocando una «lectura ordenada» del texto. El espacio ha dejado de ser considerado como un valor artístico a priori en el proceso de estudio científico que se haga de la imagen. El espacio neutro hace perder a la imagen verosimilitud naturalista como una totalidad, y gana claridad expositiva en la transmisión de su información especializada; es decir, científica.

En España; por otra parte, la ilustración científica sobre insectos durante el siglo XVIII fue escasa. Más adelante, en los inicios del Diecinueve, aparecen obras que son herederas de la tradición iconográfica descrita. Me refiero a los trabajos de Ignacio Bolívar Urrutia (24), que construye sus imágenes sobre la base de espacios neutros, aunque con ciertas matizaciones que lo alejan, definitivamente, de todo "condicionante» naturalista al modo de los observados en las obras de Roesel y Hoefnagel. El fondo se propone tan sólo como un soporte o una superficie de contraste de los dibujos.

\subsection{Peces}

Juạn Bautista Brú se convirtió en una de las figuras más sobresalientes del disegno sobre peces en el Dieciocho español. Brú de Ramón, «pintor y disecador» del afamado Real Gabinete de Historia Natural de Madrid des- 
de el año 1777 (año de su fundación) hasta 1799, desarrolló una intensa labor en el campo de la ilustración científica, destacando en el campo de la ilustración de animales y -muy especialmente- el dibujo de especies marinas que habitan (algunas de ellas todavía lo hacen) nuestras costas. En trabajos como: Colección de los peces y demás producciones marítimas de España (1796), en la que aparecen 136 láminas dibujadas y grabadas por este artista valenciano, Brú deja constancia de su habilidad y técnica depurada en el manejo del grabado al «agua fuerte». Un año antes de esta publicación, ya Brú había dado muestras de su talento en 357 láminas realizadas para el Diccionario Histórico de las Artes de Pesca Nacional, obra en 5 volúmenes de Antonio Sanz Reguart, Comisario de Guerra y Marina para la época.

Los trabajos de este valenciano, meticuloso y delicado con el buril, se encuentran a un nivel muy alto respecto a las producciones europeas sobre este tema. Obras como las del alemán Peter Simon Pallas, Spicilegia zoologica (1771), se hallan en la línea de las composiciones de Brú. Planteamientos formales y constructivos como los utilizados por aquél: espacio neutro, detalles anatómicos (boca), distintos puntos de descripción y observación (desde arriba, desde abajo, lateral), están presentes en los trabajos de Brú. En algunos casos - especialmente en los grabados de Pallas- las figuras aparecen numeradas, remitiéndonos a un texto que detalla la información contenida en las láminas. Los detalles anatómicos son abundantes. Hay una fuerte insistencia en representarnos despieces de aquellas partes del interior y exterior del animal: aletas, esqueleto; boca, membranas, etc.; siguiendo, por otro lado, los planteamientos clasificatorios del sueco Pehr Artedi establecidos en su Ichtyologia (1738). Según Artedi, las descrripciones de las partes internás y externas de los peces servían para establecer sus géneros, propuestos en número de 45 , según el número de radios de los oídos, posiciones relativas de las aletas, su número, partes de la boca y dientes, conformación de las escamas, partes internas: estómago y apéndice de ciego, etc.; sin duda, todos éstos elementos característicos de los dibujos de Brú. Asimismo, este modelo iconográfico basado en los planteamientos de Artedi se extendió a las producciones que en este ámbito se realizaron durante las expediciones científicas de espanonoles a América. Desde el proyecto de la Expedición de Límites al Orinoco (1754-1761) en la que participa Pehr Löfling, discípulo directo de Carlos Linneo, hasta expediciones como las realizadas años más tarde a los Reynos del Perú y Chile (1777-1787) o la Expedición alrededor del mundo (1789-1794), el modelo descriptivo sobre peces y especies marinas reseñado en la obra de Brú. si- 
gue vigente. Primero, por tratarse de un modelo muy útil y claro en sus intenciones; y segundo, porque una vez asentadas oficialmente las ideas y métodos clasificatorios de Linneo (la propuesta ictiológica de Artedi que es recogida íntegramente por éste y se introduce en España de manos de su discípulo Löfling) pasa a formar parte inseparable de los planteamientos científicos de los naturalistas españoles.

En resumen, hemos abordado a lo largo de este trabajo el desarrollo de ciertos tipos de imágenes científicas sobre animales, habitantes de nuestro "Zoo de papel» durante los siglos XVII y XVIII, preferentemente. Nuestro estudio nos ha llevado a desarrollar aquellos aspectos y características que las significan: desde el uso de los elementos formales del lenguaje artístico hasta su concreción dentro de ámbitos del discurso científico.

Mis intenciones han quedado limitadas a las posibilidades que me ofrecía un artículo de revista. Solamente han quedado apuntados aspectos que puedan abrir las puertas del conocimiento y el estudio de la historia de las imágenes científicas; las puertas a esta maravilloso y.apasionante "Zoo de papel».

\section{NOTAS}

(1) Gombrich, E. M. (1979): Arte e ilusión. Estudio sobre la psicología de la representación pictórica. Barcelona, Gustavo Gili.

(2) Idem, opus cit., p. 84.

(3) Sobre los arquetipos, véase la obra de Gombrich citada, en las páginas de la 80 a 86 .

(4) Le Brun, $\mathrm{C}_{\text {H. }}$ (1696): El método para aprender a dibujar las pasiones. París.

(5) Della Porta, G. B. (1586): De humani.physiognomia. Nápoles.

(6) Las imágenes artístico-científicas se pueden definir como aquellas representacionés en las que en su construcción se han utilizado elementos considerados por la tradición artística como elementos de utilidad artística (formas, volúmenes, colores). Obteniéndose de sủ puesta en escena (representatividad) una propuesta científica, de forma expresa y seleccionada, de una información especializada.

(7) Carrete Parrondo, J (1982): «Divertimento y trascendencia. Estampas de María Eugenia de Beer, 1640-1652», en: Cuaderno de aves para el príncipe. Estampas de María Eugenia de Beer siglo XVIII. Gustavo Gili, pp. 3 a 14.

(8) Idem., opus cit, p. 11.

(9) Véase, Maluquer Sotres, J. (1982): «Aves en el siglo XVII castellano», en: Cuaderno de aves para el príncipe...Estampas de María Eugenia de Beer, siglo XVII, opus, cit., páginas 1 a 11 . 
(10) El marco interior, dentro de las composiciones de matiz científico, se puede considerar como un elemento que delimita el espacio de representación del que no lo es. Su empleo dentro de la botánica del Dieciocho fue muy extendido. Convirtiéndose en un elemento de identificación de este tipo de ilustraciones.

(11) MaluQuer Sotres, J. (1982): «Aves en el siglo XVII castellano», en: opus cit., p. 9.

(12) Hemos manejado la edición española ya reseñada de José Clavijo y Fajardo.

(13) Entre ellos se encuentran Pablo Alabern y J. F. Asensio. Ambos, y en ese orden, grabadores de los ejemplos que citamos en este artículo.

(14) El espacio escenográfico se refiere en contraposición al espacio neutro. Mientras en el primero las figuras se introducen en una decoración, a modo de un decorado, en el segundo hay una falta de referencia a cualquier tipo de decorado, siendo las figuras representadas las que conforman la propia idea de espacialidad.

(15) Véase la nota anterior.

(16) «El tipo, explicará Quatremère de Quincy, es la constante respecto a la cual puede y deben darse variantes específicas que modifiquen su forma, pero no su estructura". ARGAN, G. C. (1987). «El valor de la "figura" en la pintura neoclásica» en: Arte; arquitectura y estética en el siglo XVIII. Madrid, Akal, p. 75.

(17) Véase López Piñero, J. M. (1982): El atlas anatómico de Crisóstomo Martínez. Grabador y microscopista del siglo XVIII. Valencia, Ayuntamiento de Valencia.

(18) Se refiere a la obra de José de Clavijo y Fajardo reseñada antes.

(19) Véase ALPERS, S. (1987): El arte de describir. El arte holandés en el siglo XVII. Madrid, Hermann Blume.

(20) Merian, M. ${ }^{a}$ S. (1730): Histoire des insectes de l'Europe dessinées d'aprés nature. Amsterdam, pp. (s.n.).

(21) ROESEL VON RoSENHOF, A. J. (1740-1759): Insecten-Belustigung.

(22) GoMBRICH, E. M., opus cit.

(23) Idem, p. 203.

(24) Bolivar y UrRutia, I. (1912-1918): Estudios entomológicos. Madrid. 


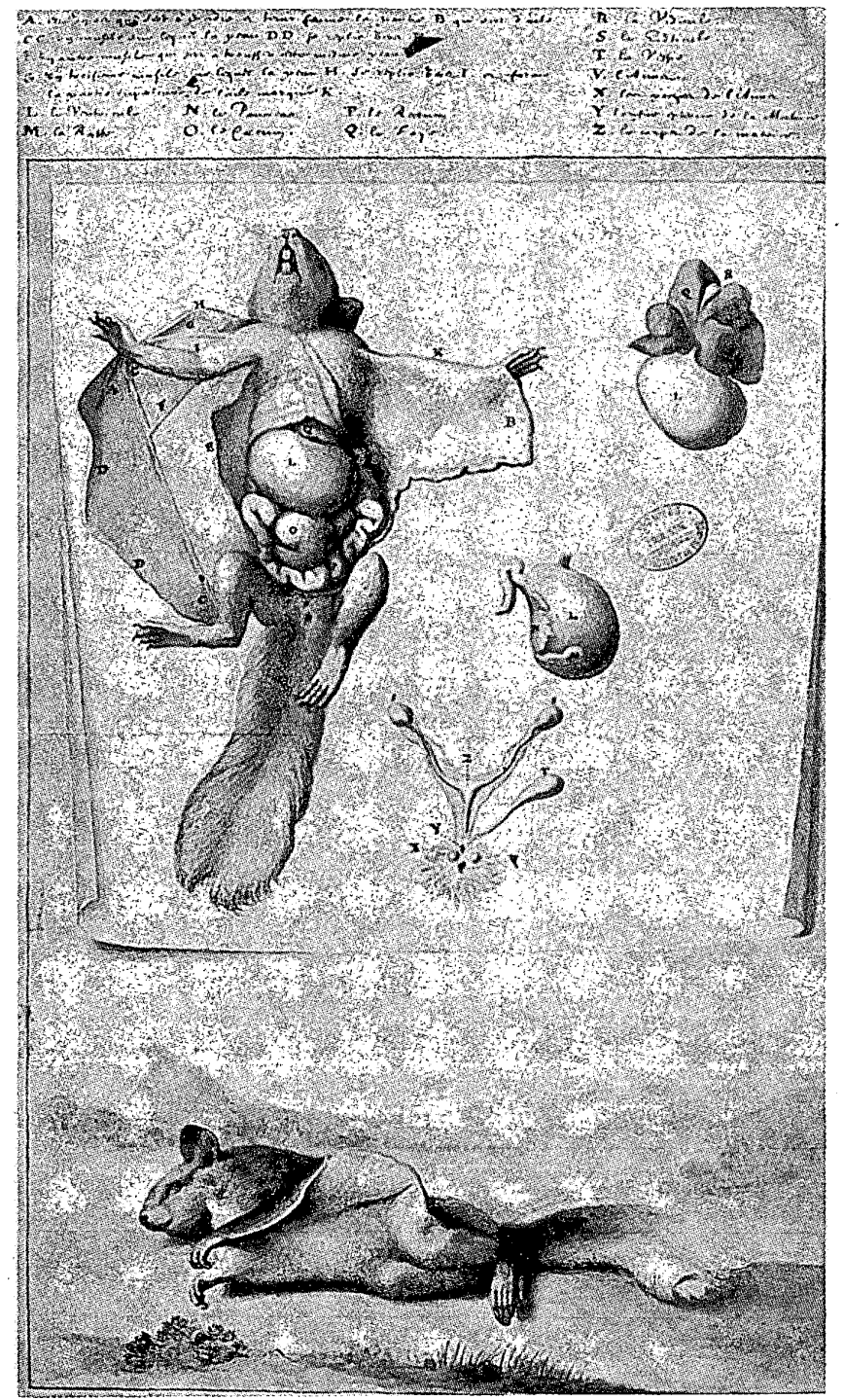

Lámina 1

Rata volante (Sébastien Leclerc). Grabado. 441 x 261 mm. Académie des Sciences, Archive, Séances, 1685. 


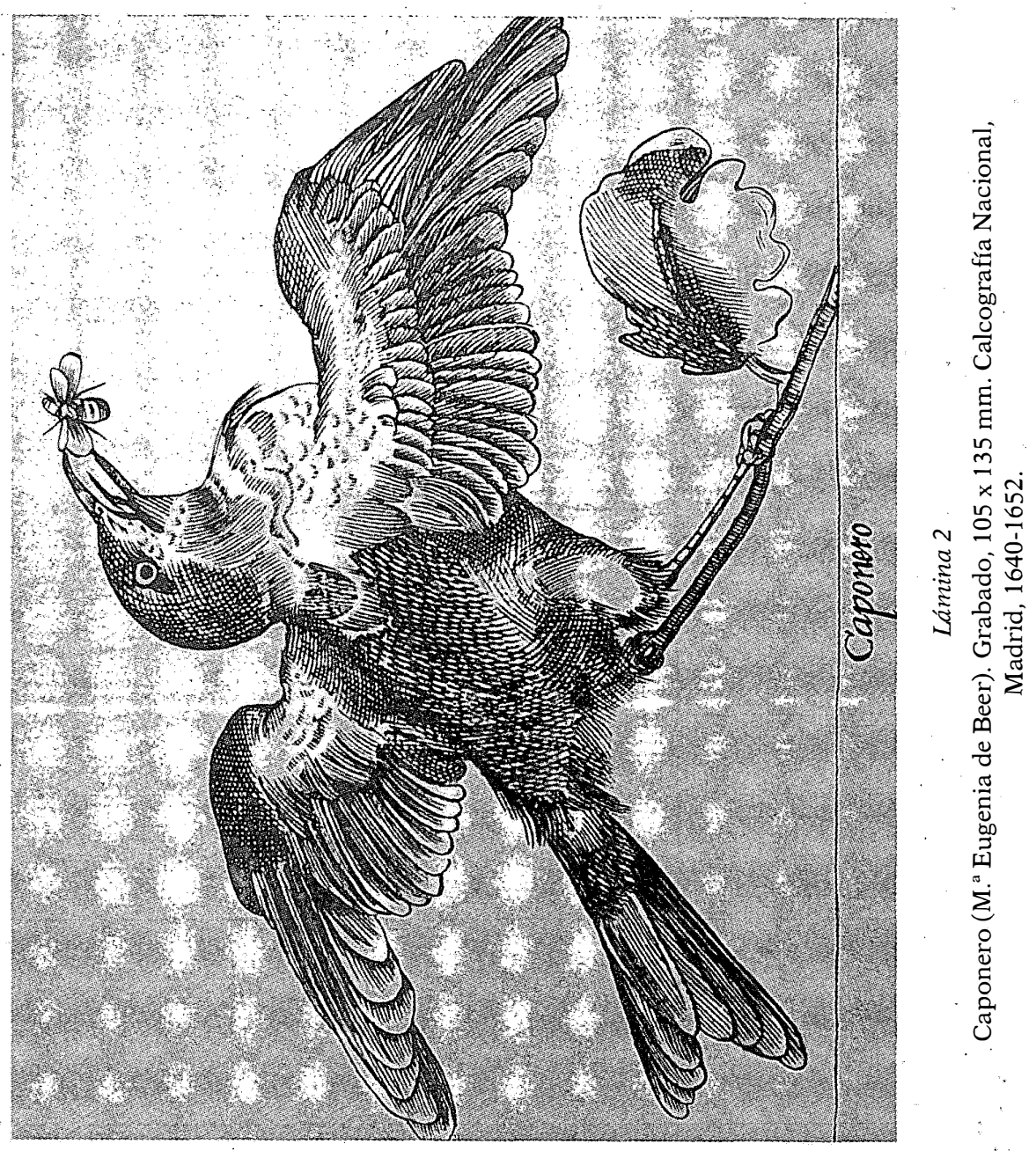




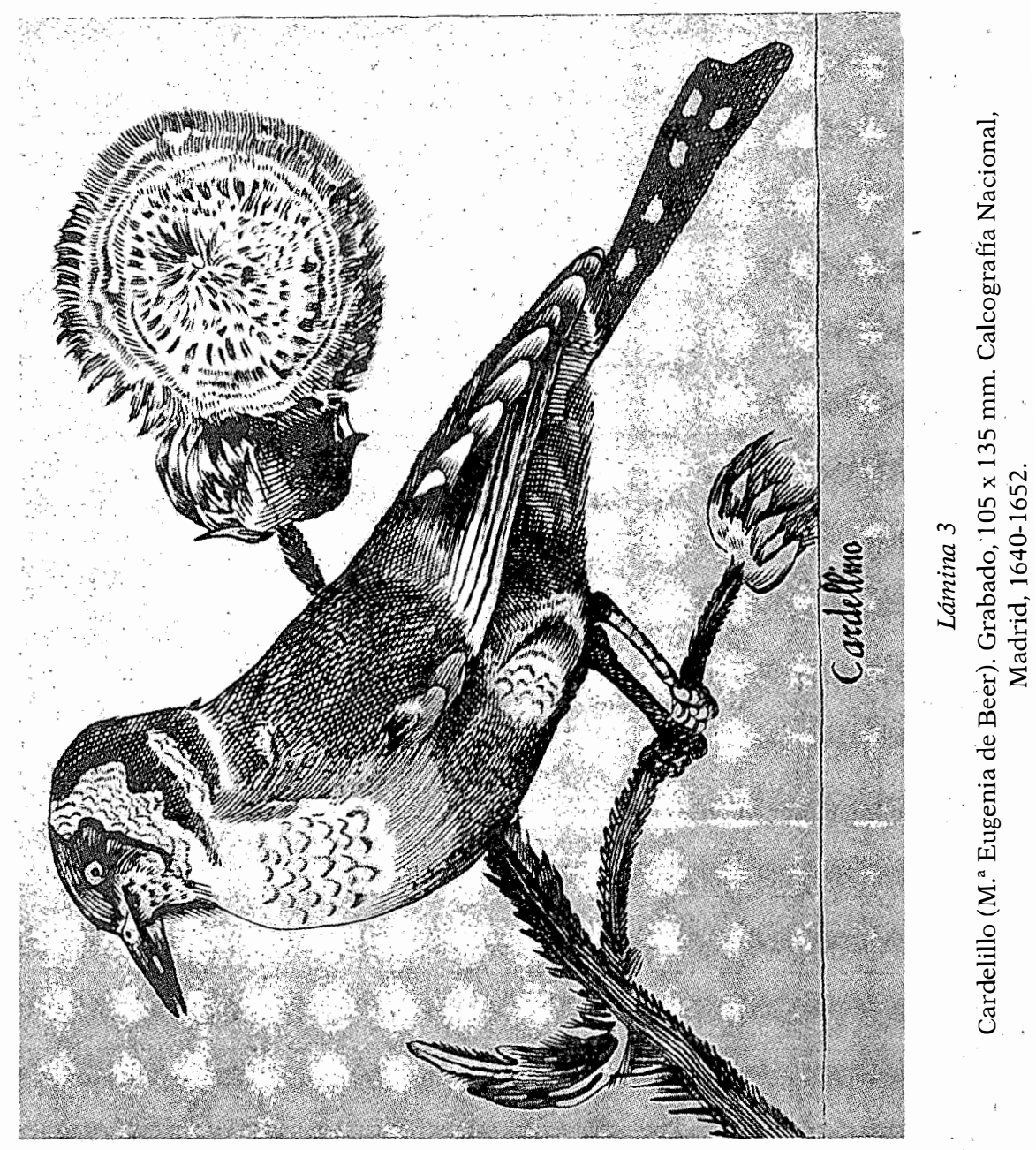




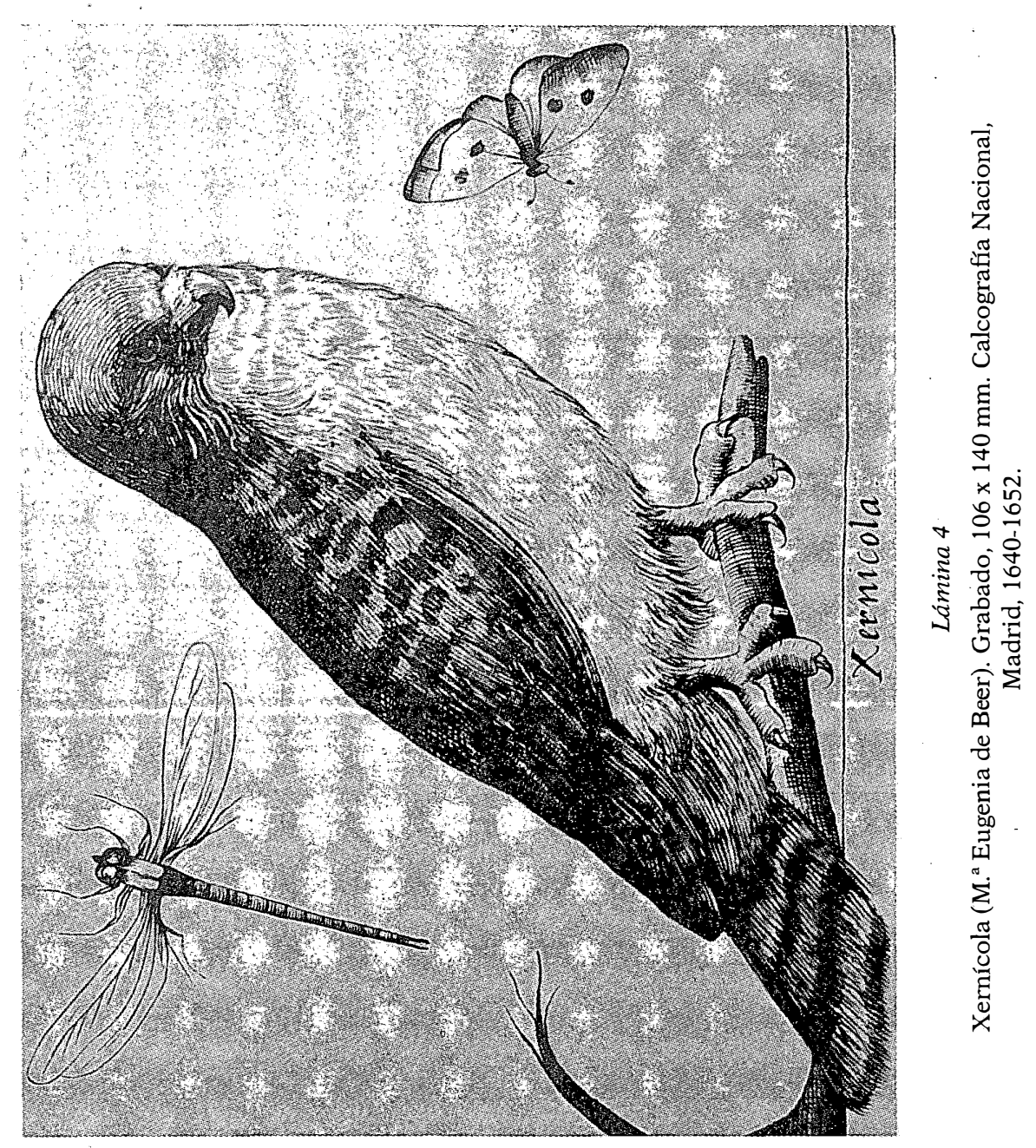




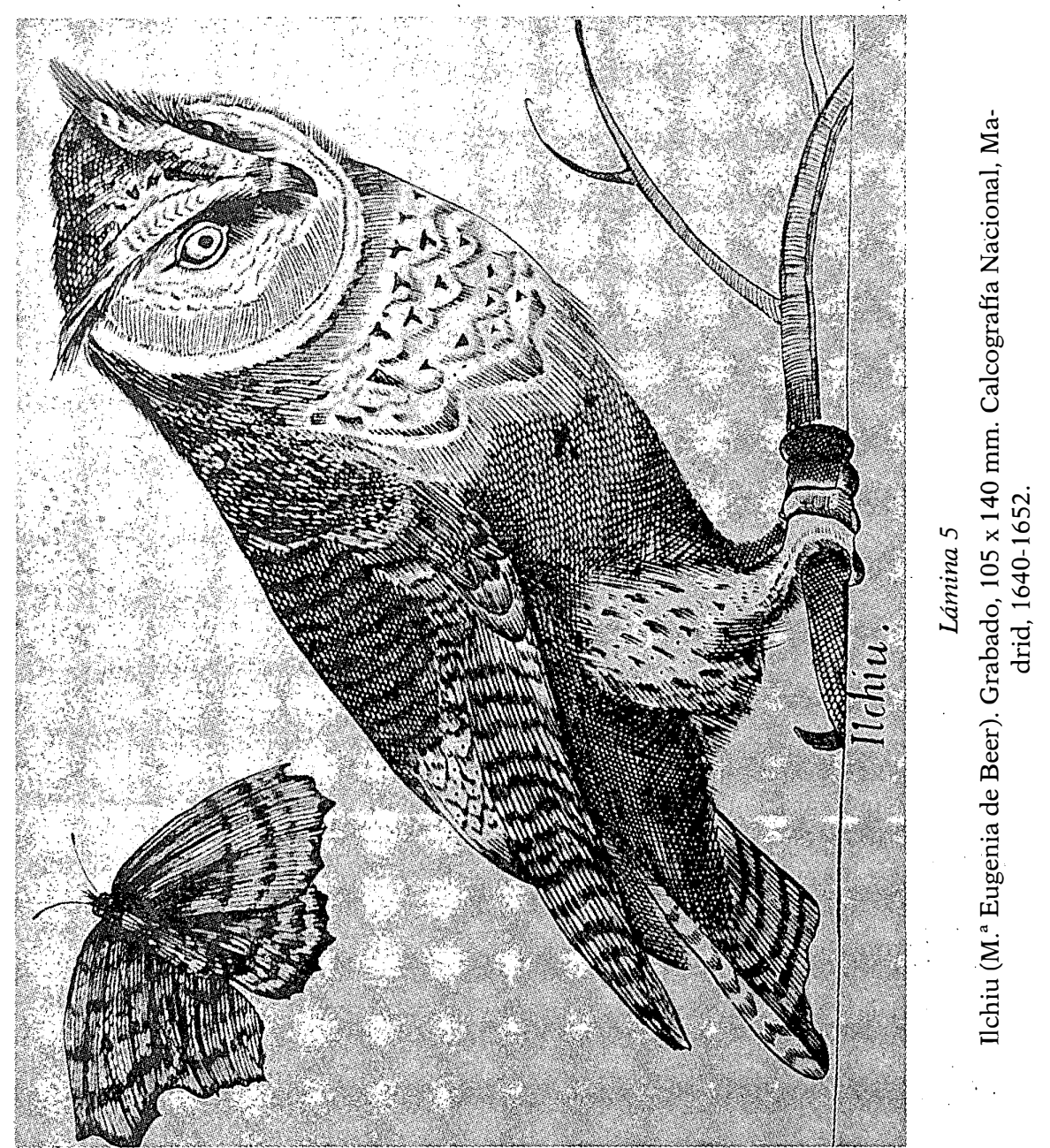

Asclepio-I-1992 


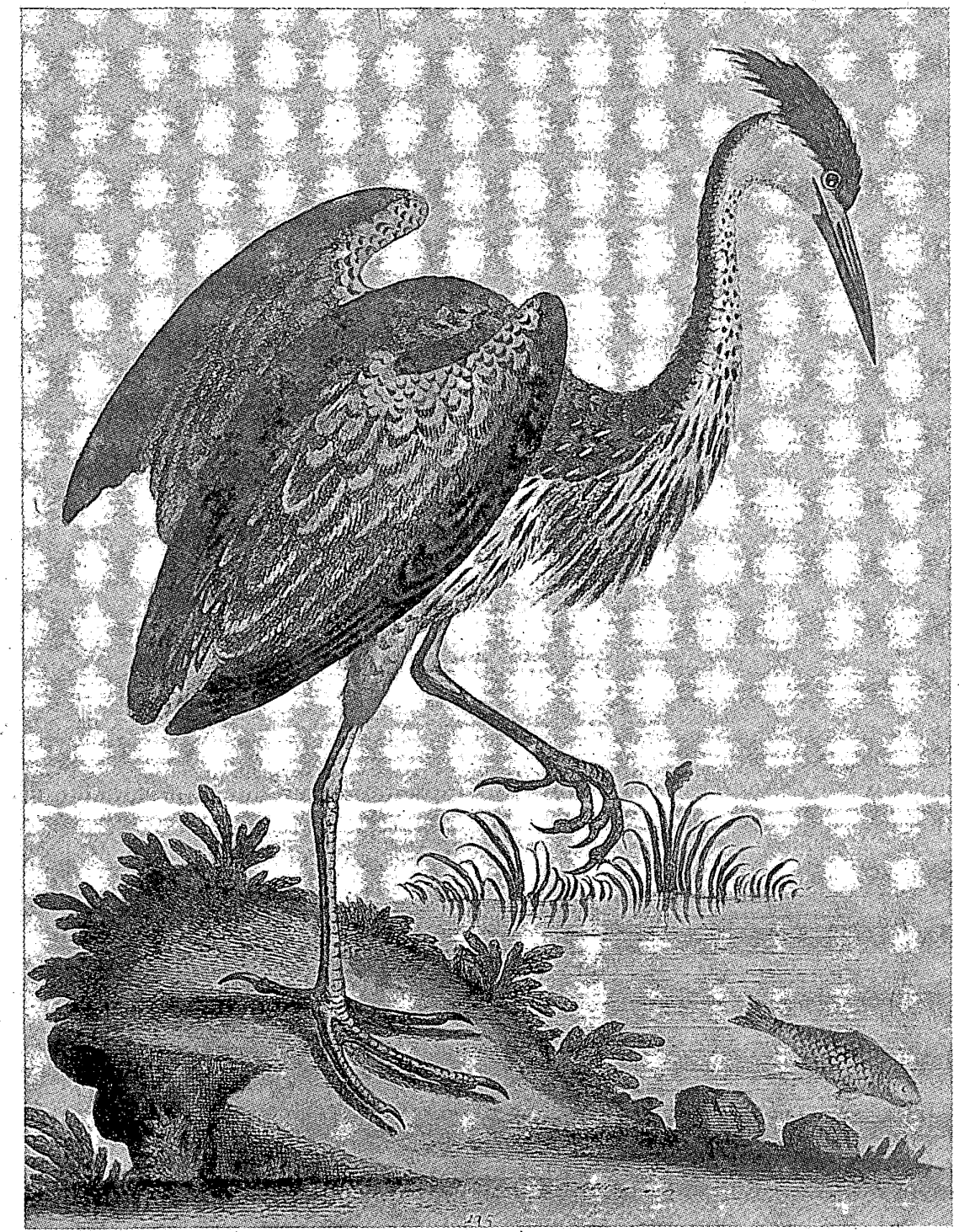

Lámina 6 .

Ardea Herodias (George Edwards). Grabado iluminado. Natural History of Birds... (1802-6). Colección, The New York Public Library. 


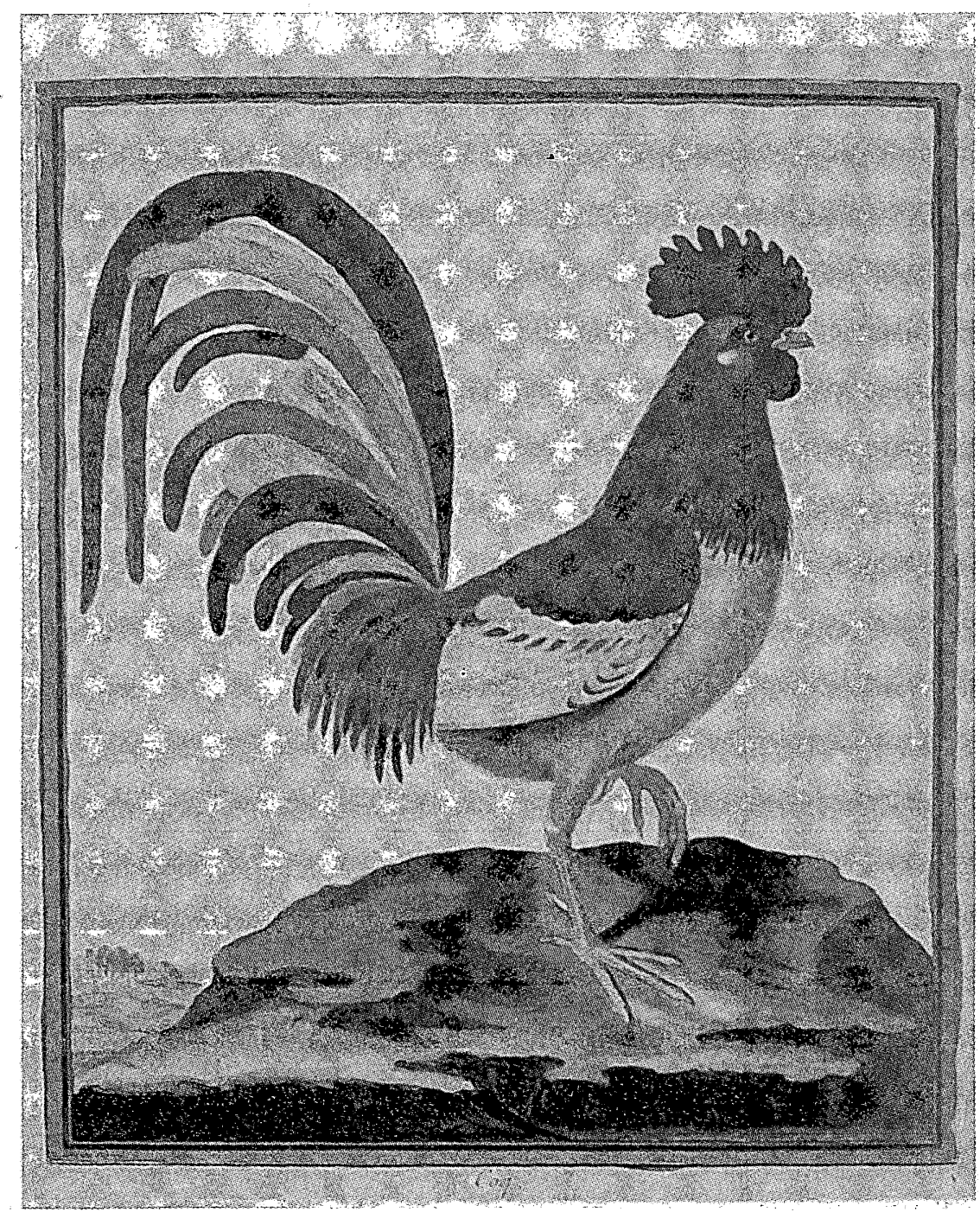

Lámina 7

Coq (François Martinet). Grabado iluminado. Planches enluminées d'histoire naturelle par Martinet, executées par Daubeton... 3 vols. (1765-83). Colección, The New York Public Library.

Asclepio-I-1992 


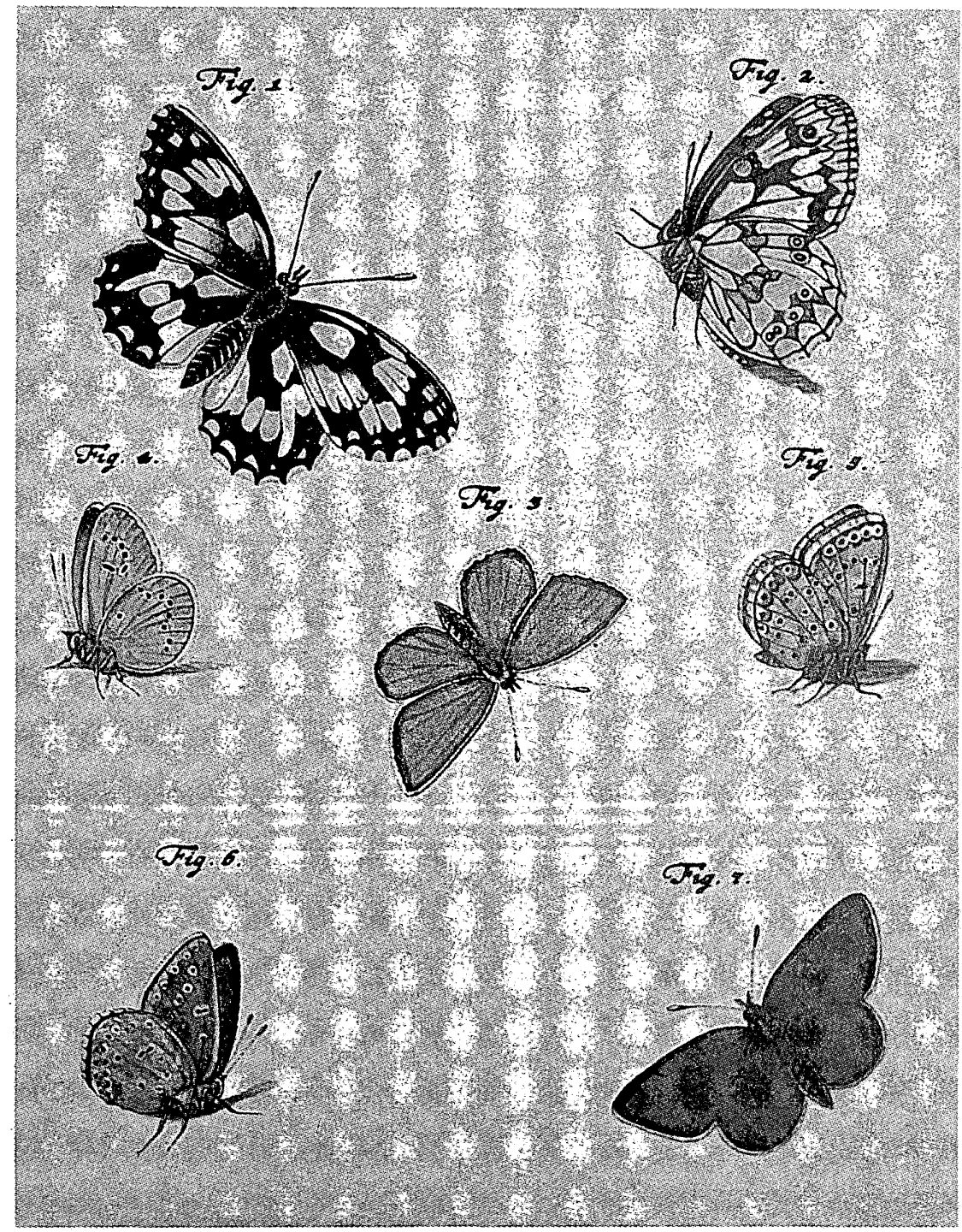

Lámina 8

Classis II. Papilionum Diurnorum (A. J. Rösel von Rosenhof). Grabado iluminado, $180 \times 215$ mm. Insecten-Belustigung, 3 vols. (1746-55). 